\title{
The Analysis of Fishing Cultural Connotation and Its Aesthetic Value Liu Zhu ${ }^{1, a} \quad$ Liu Dongyao ${ }^{2, b}$ \author{
264300, China \\ a,b104873536@qq.com
} \\ ${ }^{1,2}$ Harbin university of science and technllogy Rongheng campus, Weihai Shandong
}

\begin{abstract}
"Harbin Science and Technology University College Students' innovation and entrepreneurship training programs for the contemporary Non-material Cultural Heritage Inheritance and innovation of the research to the promotion of" fishermen Kaiyang, Xie Yang Festival "for cases of" research "
\end{abstract}

Keywords: Fishing culture; connotation; aesthetic value; analysis

\begin{abstract}
China is abundant in fishery and also is the most developed country in fishery. Fishing culture is one of agricultural cultures. It is the sum of tangible culture, intangible culture and system culture with circulation and inheritance created by fishermen in fishing producing activities for a long time! In order to study fishing cultural connotation and its aesthetic value, the paper constructs the structure of fishing cultural connotation, establishes an evaluation system for aesthetic value of fishing culture based on it, and conducts aesthetic value evaluation on research objects (including 4 areas) by beginning with humanity, social influences and influences of cultural aesthetics. The research shows that aesthetic value of fishing culture is equipped with its own value in every area. The aesthetic value of Shipu Fishing Port City is the highest and is called as a Xiangshan folk culture village, Chinese fishing village, and holiday resort. The aesthetic value evaluation of fishing culture constructed in the paper has a certain application and reference value.
\end{abstract}

\section{Introduction}

China is abundant in fishing and has a long history in fishing culture. Fishing ${ }^{[1,2]}$ has the original meaning of catching fish and is a production mode for fishers to catch fish at the seaside. Nowadays, it has formed time-honored fishing culture in China. It is closely related to the life of fishermen and permeates into various aspects, including politics, economy, society, culture, production and life. Fishing culture with Chinese characteristics is extremely valuable cultural treasury and cultural gold mine having potential development. Nowadays, under the background proposed by ocean century, fishing culture throws off charming splendor and unique academic charm for sense of sea, likability, culture and all-important realistic significance. Thus, the academic circle pays more attention to concerning fishing culture, and related research is also increasingly abundant.

The study regards fishing culture as the research object, applies theory of cultural change proposed by a cultural anthropologist Malinowski to study and analyze fishing culture in it, namely fishing culture takes place changes in external form and internal structure with the development of social history. With long-term accumulations and deposits, fishing connotation is explored. Moreover, the paper applies rural sociology, history and literature, etc., to do cultural interpretation on related connotation of fishing culture, analyzes changes of fishing cure, and evaluates development status of fishing culture and value.

\section{Fishing Cultural Connotation}

Fishing culture is an important part of human culture and not only includes some fishing production modes, including fish catching, cultivation and catch processing ${ }^{[3,4]}$, but also includes unique life, customs, and religious faith of fishermen. It is the sum of tangible culture, intangible culture and system culture with circulation and inheritance created by fishermen in fishing producing activities for a long time. The structure chart of fishing culture is shown in Figure 1. 


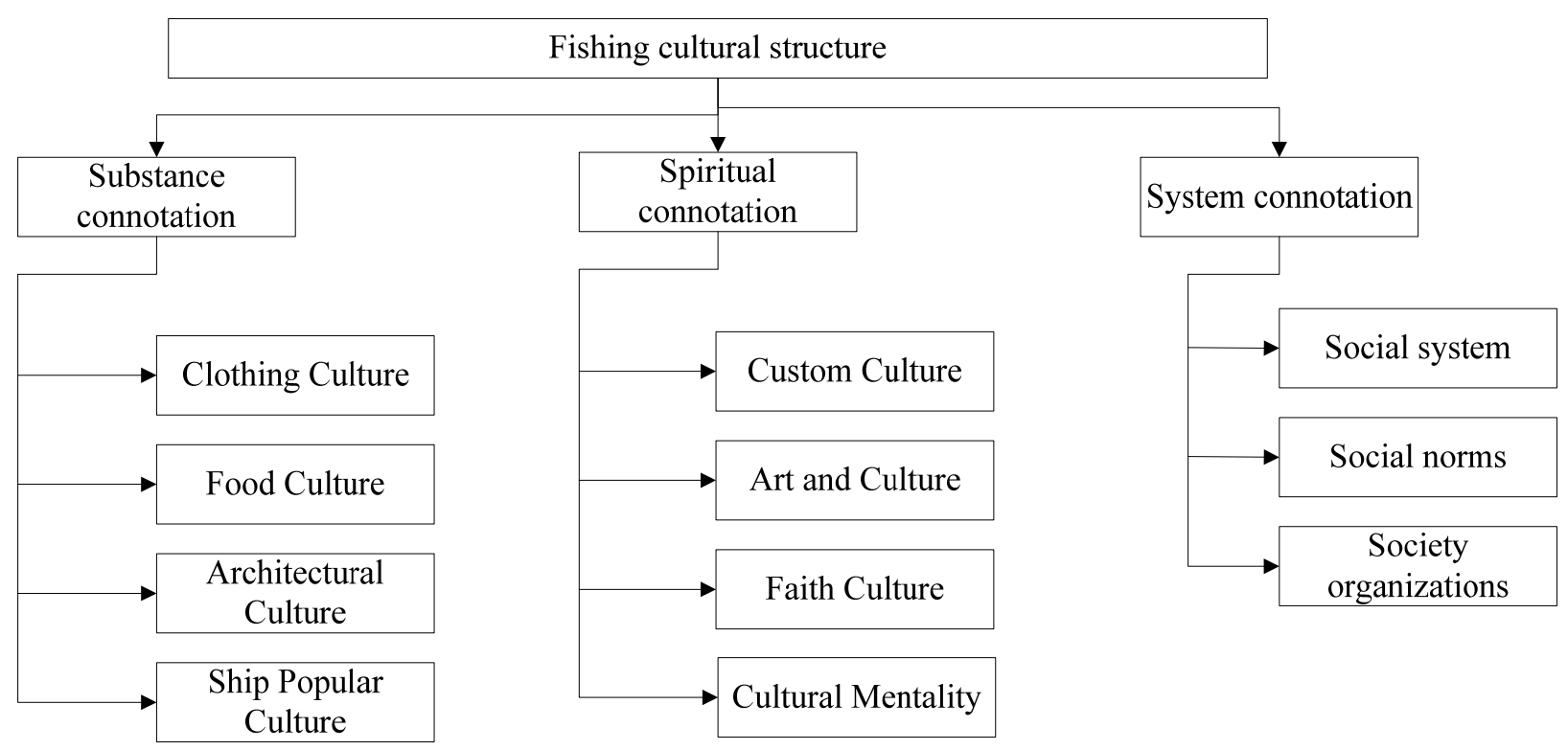

Fig. 1 Structural Figure of Fishing Culture

Substance connotation creates a group of substance products and some cultural traits for the sake of satisfying human survival and development, including basic necessities of life. Substance connotation of fishing culture mainly includes clothing culture, food culture, architectural culture and ship popular culture. Spiritual connotation is cultural traits with immaterial form created in the social and historical practice process of humans, customs, arts, faith and mentality etc. Non-substance connotation of fishing culture mainly contains custom culture, art and culture, faith culture, and cultural mentality. System connotation satisfies demands of human survival and social development and creates a group of standardized cultural traits to standardize organizational system. System connotation of fishing culture mainly involves in social system, social norms and social organizations. As shown in Figure 2 and Figure 3, they display creative figures of fishing culture. The originality embodies local cultural connotation.
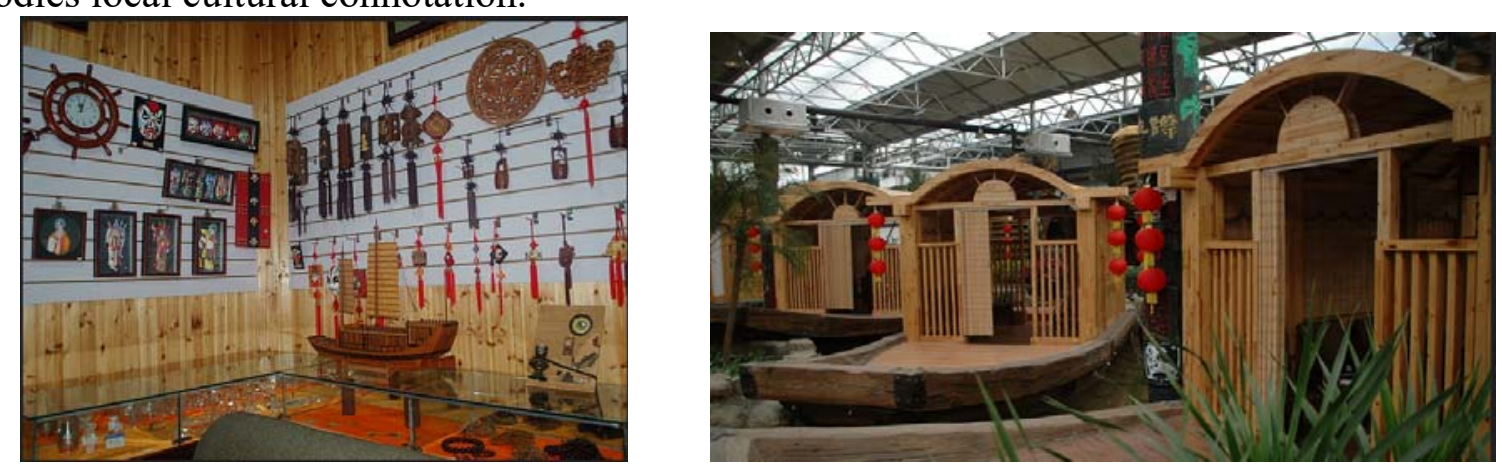

Fig. 2 Creative Design of Fishing Culture Fig. 3 Design of Fishing Cultural Park

The fishing culture exhibition in an area is shown in Figure 4. The exhibition integrates housing characteristics of current fishermen with inland residences partially. "Traditional fisherman housing is decorated by using pearl, shellfish, and leather goods of marine fish and marine animals. TH external structure and carved beams and painted rafters for a courtyard are represented by dragon, fish, boat and anchor, etc. The commonest one in murals and paintings is "the sun rising from the ocean" and "plain sailing" and so on. All of these embody characteristics of fisherman society". In other words, they depend on ocean for all necessities of life. This undoubtedly embodies a close relation between fishing culture and ocean. 


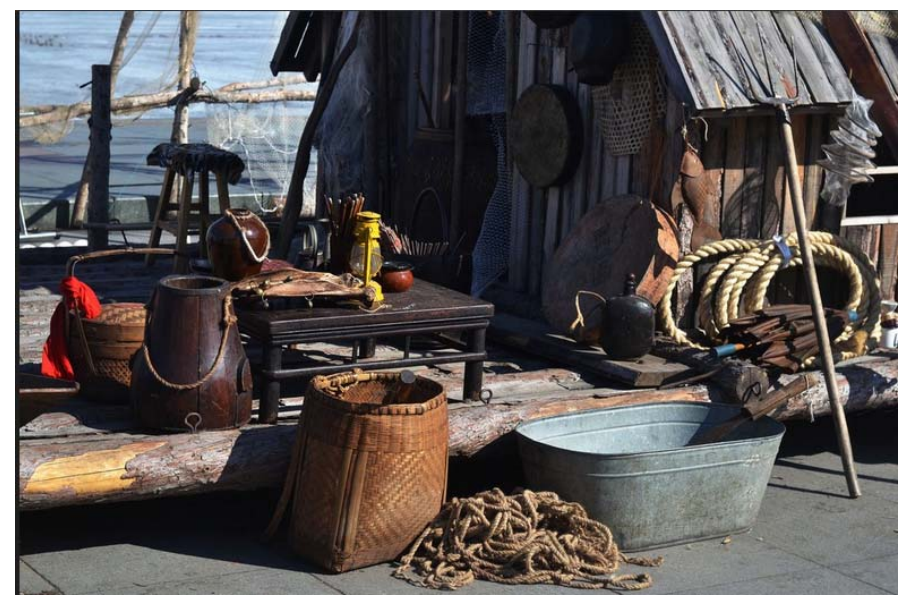

Fig. 4 Fishing Culture Exhibition

The Kaiyang Festival and Xieyang Festival in the Xiangshan area are shown in Figure 5. Kaiyang Festival and Xieyang Festival are spiritual ballast of fishermen. They have the core of sacrifice. The original meaning of these activities hopes that deities could bless plain sailing and come back with fruitful results. It has some characteristics, including diversity of sacrificial offering objects (the Goddess of the sea, City god and the Dragon King), universality of sacrificial offering sites (temple, coast, dock, port and fishery, etc), diversity of sacrificial forms and contents(including worship boat dragon, Kaiyang Festival, Xieyang Festival, sacrifice Xiaohai, and Peace Festival, and uniqueness of sacrificial purposes. They belong to spiritual ballast of the masses in fishing areas and a kind of fishing culture with original ecology.

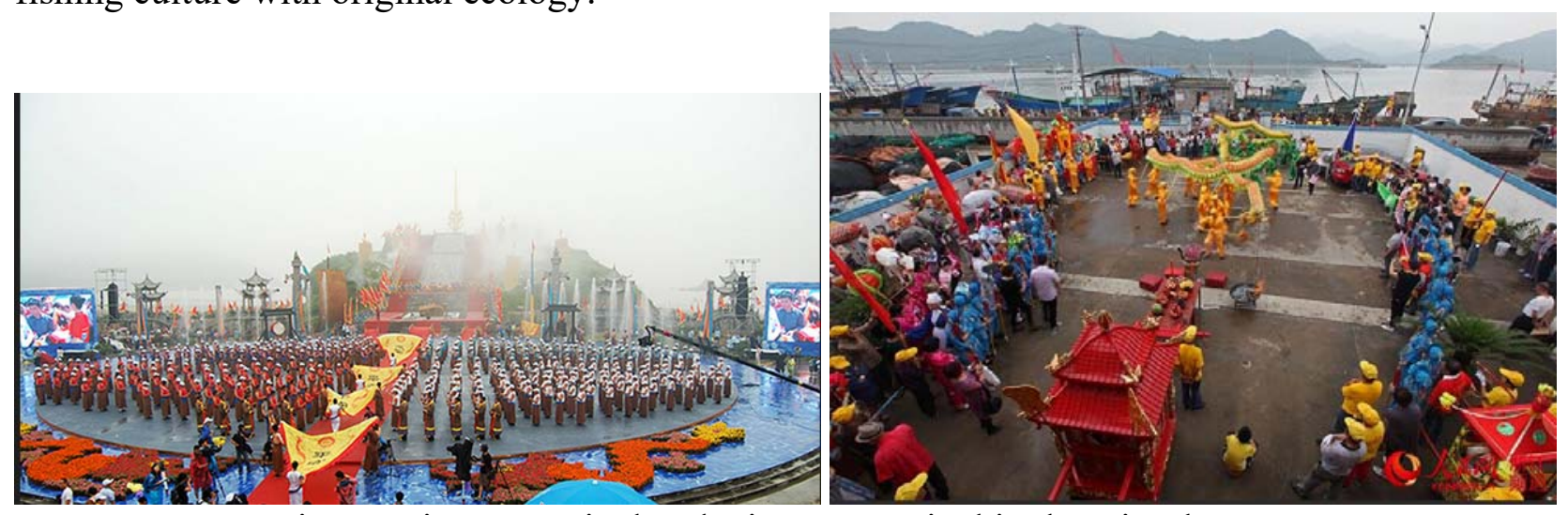

Fig. 5 Kaiyang Festival and Xieyang Festival in the Xianshan Area

\section{Aesthetic value evaluation and analysis of fishing culture and its analysis}

Construction of aesthetic value evaluation and analysis of fishing culture and some of things

The fishing culture in the era of fishing and hunting has already had cultural phenomena with profound connotation ${ }^{[6]}$. These widely impact culture and social life of human people. Cultural value and social value equipped by fishing culture also need to self-audit, settle, explore and study and carry forward new situations. Inheritance of fishing culture is the demand to carry toward excellent traditional culture of China, cultivate national emotions, and have confidence in local culture. What's more, it is also the demand of economy and social development and is the realistic guiding significance of fishing culture. The study on aesthetic value evaluation on fishing culture is shown in Figure 6 . The study analyzes in multiple aspects of humanity, society and cultural influences, etc., to construct talented evaluation. 


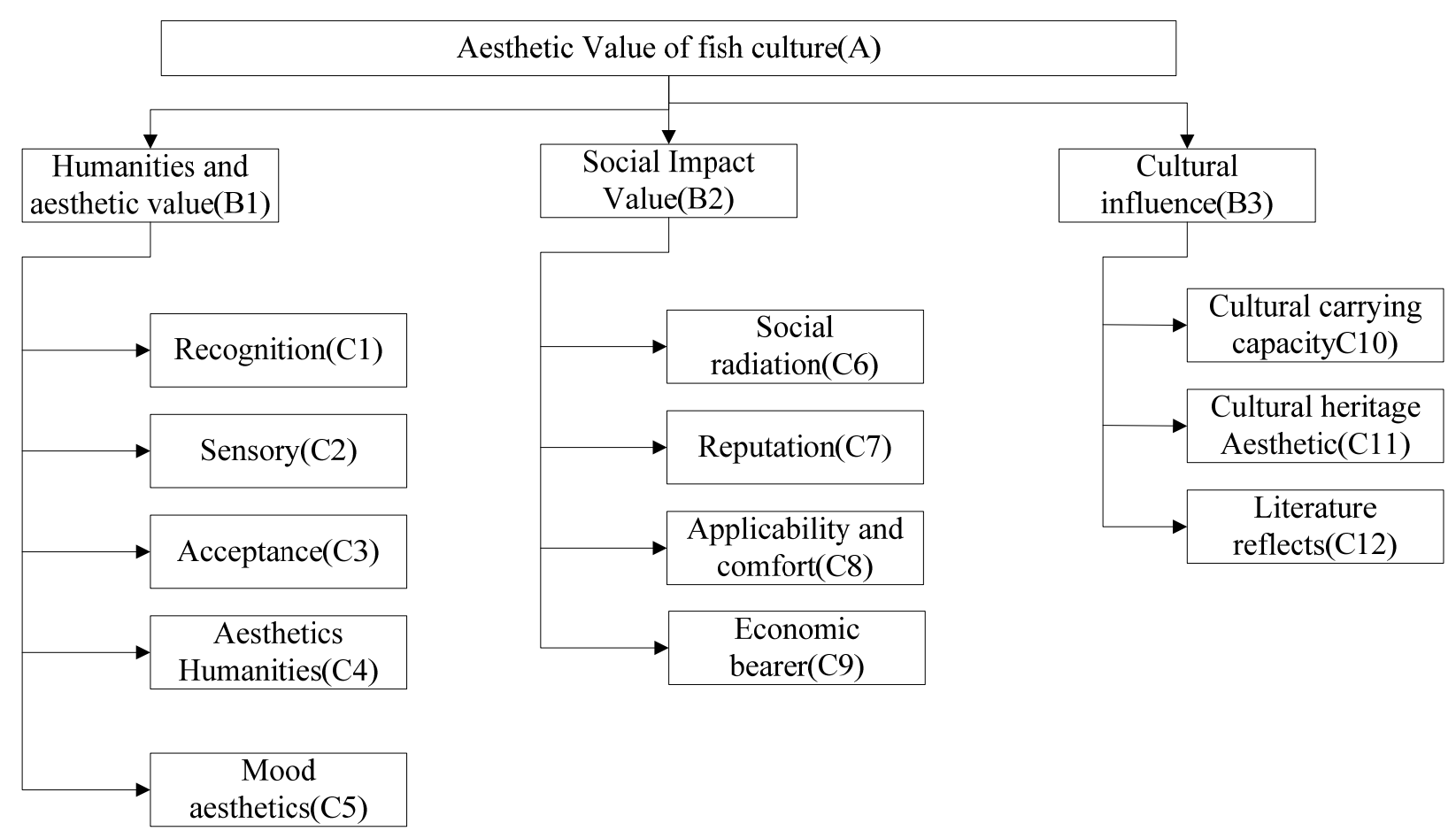

Fig. 6 Cultural Aesthetic Value Evaluation System

The paper selects a fuzzy synthetic evaluation method to give overall consideration to multiple different things and objects. Influences of multiple factors are common to judge good or bad things, so as to do reasonable evaluation. The method divides different factors into ordered levels and judges matrix setting on the same level. After evaluation system sets up membership function of corresponding evaluation factors, weights of different elements are obtained by comparative analysis between them. According to the weight, fuzzy synthetic evaluation is applied to obtain optimal schemes.

Factors on the same level of the evaluation model for fishing culture development of tourism resources are compared with respect to influence or important of the upper level. The judging matrix $\mathrm{M}\left(\mathrm{a}_{\mathrm{ij}}\right)_{\mathrm{mxm}}$ is constructed. Aiming at different importance of every index in the evaluation, scale is used to express equal importance, slight importance, significance importance, strong importance, and extreme importance, indicating that middle value for judging above-mentioned middle value of adjacent judgment by making a comparison between them(the importance scale by comparing the latter with the former uses the reciprocal of importance scale by comparing the former with the latter. )

Product of element in every line is obtained and obtains $\mathrm{n}^{\text {th }}$ root. Results are normalized to obtain weight between index on a level relative to upper index. In order to ensure construct an evaluation index weight system of cultural tourism resources with relative objectivity, fairness and sicentificity, the author invites experts and scholars in geography, tourism, culture and economy to fill in the judging matrix, endow value to acquire the mode, input settled results in a computer to acquire weight of index.

In order to ensure the constructed matrix conforms to requirements, it is necessary to do consistency check on it. The computed results show that all judging matrixes pass the consistency check. Otherwise, it is necessary $t$ adjust it appropriately until it passes the consistency check.

In order reflect aesthetic value status of fishing cultural tourism resources comprehensively, it is also necessary to calculate aesthetic value influences of tourism resources on the basis of establishing evaluation index system and corresponding index weight and vector. Because every index in evaluation index system reflects the aesthetic value status of fishing culture from different levels and sides, development potential evaluation of fishing cultural tourism resources is a comprehensive system. The study applies the linear weighting function (namely comprehensive scoring method) to do comprehensive evaluation on it, and its function expression is shown as follows: 


$$
E=\sum_{i=1}^{n} \lambda_{i} P_{i}
$$

In the formula, $\mathrm{E}$ is the aesthetic value comprehensive index of fishing culture; $\lambda_{i}$ is the weight of the $i^{\text {th }}$ evaluation factor; $\mathrm{P} i$ is the score of the $i^{\text {th }}$ evaluation factor; $n$ is the number of evaluation factors. 10 -score system is applied to score a tourist attraction. The acquisition of evaluation factor scoring is conducted by consulting with related experts, scholars, and staff in tourism departments.

\section{The Aesthetic Value Evaluation Analysis of Fishing Culture}

In long-term practice of tilling the sea and fishing, fishermen in Xiangshan learn to how to make a boat and weave fishnet, as well as common sense of producing various fishing tackles, master time for going to sea and return and operation at sea, and form a cultural phenomenon with the core of fishing." Thus, lots of proper production and lifestyles of fishermen in Xiangshan contain a series of ocean fishing culture tourism resources, including tradition of fishermen, clothing of firemen, yu-drum, light, horn, building of fishermen, boat decoration of fishermen, medical skills of fishermen, medical diet, and festivals and celebration, and so on. Moreover, it continues with the fishery production and lifestyles until now. The paper selects 4 typical cultural villages in scenic spots as research objects. Area 1 is the Songlanshan Seaside Resorts; area 2 is the Chinese fishing village; Area 3 is the Shipu fishing port, and area 4 is the folk culture village in Xiangshan.

Table 1 Aesthetic Value Evaluation Results of Fishing Culture

\begin{tabular}{ccccc}
\hline Evaluation index & Area 1 & Area 2 & Area 3 & Area 4 \\
\hline C1 & 4 & 7 & 9 & 9 \\
C2 & 4 & 6 & 8 & 6 \\
C3 & 4 & 6 & 8 & 8 \\
C4 & 5 & 6 & 7 & 8 \\
C5 & 7 & 7 & 8 & 7 \\
C6 & 6 & 7 & 8 & 7 \\
C7 & 7 & 7 & 8 & 6 \\
C8 & 5 & 6 & 9 & 8 \\
C9 & 7 & 8 & 8 & 5 \\
C10 & 8 & 8 & 7 & 7 \\
C11 & 8 & 8 & 8 & 6 \\
C12 & 8 & 8 & 8 & 5 \\
\hline
\end{tabular}

It can be observed from the data in the table that the Chinese fishing village is national 4A scenic spot and is a good place for relaxing on holidays, sports animation and fishing coastal recreational area. It integrates sunshine, sand, coast, and village. There is an ocean museum, exhibition hall of Kaiyu Festival, platform for sacrificing, and sunshine and sunshine". It belongs to famous festival activities in coast time of Zhejiang. It is a place for stamping sand bench on double third day. In addition, it is also the parallel session of Chinese Kaiyu Festival. However, compared with Shipu Fishing Port city, the resource value, resources bearing ability and resource influence in the scenic spot are slightly inferior. Market conditions are its advantage. Xiangshan Folk Culture Village was created by a famous root carving artist named Zheng Zhenben in China. There is root carving art gallery, painting and calligraphy gallery, ancient furniture, market development condition, stone implement and pottery. All of them display artistic connotation of fishing culture in Xiangshan. However, its resource influence, market development conditions, and market requirement demands rank behind in scenic spot in these areas. This is the bottleneck to restrain the tourism development. Songlanshan Coastal Seaside Resort is national.

Organizational coordination of graphics, tables, colors and formats resents the form of beauty and reaches visual effects of beauty. Visual language in interactive experience design has the irreplaceable status in exhibition. In most of applications, visual language is the most important pattern of manifestation in the theme exhibition with the exhibition form of interactive arts. In recent years, sightseeing and relaxation are flourishing increasingly. The relaxed fishery generated by 
combining fishery and fishing culture is also one of projects for relaxation and tourism. Parts of fishermen with new concept master the social fashion properly, are good at using idle boats and fishing port facilities to transform into employees of relaxed fishery. Thus, they have no need to take the risk of strong breeze and cross sea, but also can own relatively higher incomes. Fishermen not only obtain the second development of career, but also drive the transformation of the entire marine fishery. "Fishery transformation" conforms to the property of nature, develops fishery resources continuously, and makes harmonious coexistence between humans and oceans. This is a career that brings benefits to our posterity. In the process of fishery transformation, it is necessary to avoid from destroying living goods and fishing facilities left in fishing villages by predecessors. Instead, it is necessary to conserve customs, buildings and implements in fishing areas. Meanwhile, fishery transformation should damage and destroy treasure left by ancestors-fishing culture, for fear that lots of valuable non-renewable cultural treasures are destroyed and cause regrets to descendants.

With the constant improvement of people's living standard and higher requirements for food security, people not only require for enough fresh foods, but also want to experience distinctive cultural perception and humanistic feelings. As a result, these fishery festivals and activities not only should be based on fish food, but also hold many activities relating to local fishing culture. For example, cultural tourism season for Bluefin tuna in Donggang, Pingtung County(Figure 6), except for selling food of Bluefin tuna and related fishing food, there are some creative food, painting kites and lanterns, as well as dragon boat contests, and so on. Moreover, it is formed by matching with neighboring tourist spots, so as to improve local popularity and drive local economic benefits.

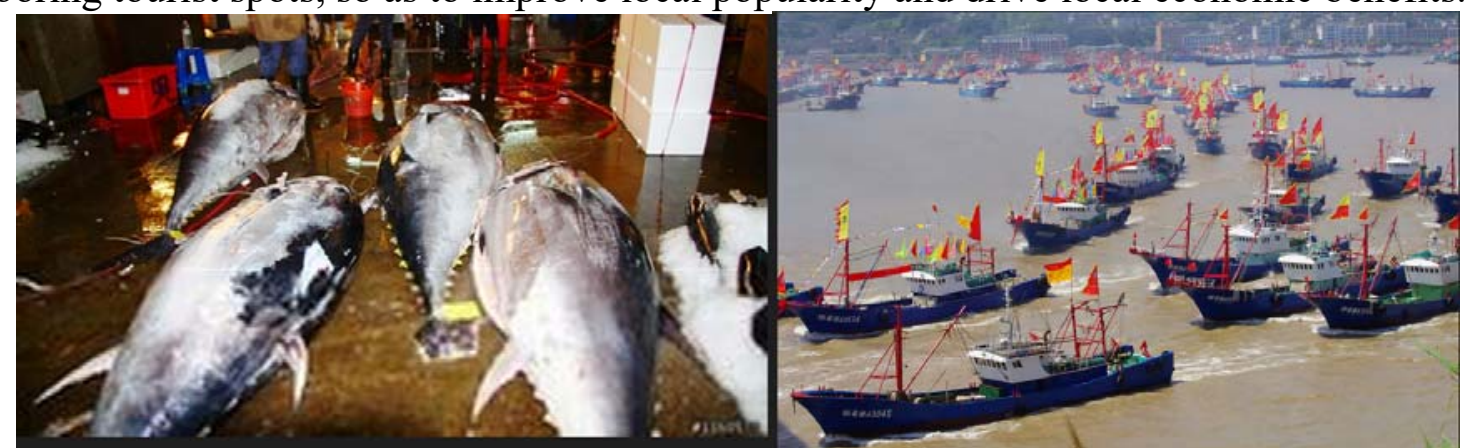

Fig. 7 Cultural Tourism Season for Bluefin Tuna in Donggang, Pingtung County $\quad$ Fig. 7 Kaiyu Festival in Xiangshan

Kaiyu Festival(Figure 7) is not a local festival anymore and has already become listed in one of 10 folk festivals in China officially. Except for value orientation in the Kaiyu Festival, specific charm displayed by the abrogated fishing culture is also an important reason for wide attention caused by the Kaiyu Festival. Nowadays, paralic environment is deteriorated constantly, fishery resources are deficient increasingly, thus survival and development of fishermen are threatened seriously. Kaiyu Festival is the fishing culture ceremony taking the responsibility of innovation, while fishing culture can arouse people's consciousness of protecting marine environment and fishery resources and further promote fishery development and improvement of fishermen's living standard. Except for the Kaiyu Festival in Xiangshan, there are different fishery festivals in different areas, with different forms and contents in China.

\section{Conclusions}

It is necessary to develop characteristic culture in fishing villages, reinforce development, settlement and protection of fishing culture resources, positively develop folk arts with fishing culture characteristics and regional characteristics, such as fishing opera and work song sung by boatmen, develop folk tourism projects of experience in fishermen's family, provide more positive literary works with the theme of fishing village, and add some elements of marine fishing transformation and fisherman transformation to present them on the stage or produce films, televisions, books and audiovisual products. This not only makes more people realize and concern the development and status of fishing villages, but also makes fishermen feel kind and accept fishery transformation 
imperceptibly. The analysis of fishing culture and aesthetic value can provide a good analysis foundation on the local. People should fully realize the role and significance of promoting marine fishery development and transformation by fishing culture and regard it as a great event to promote economic and social development in fishing areas, promote fishery structure adjustment and increase incomes of fishermen. Inheritance of fishing culture is the demand for carrying forward Chinese traditional culture, cultivating national emotion, increasing cultural confidence, and promoting economic and social development. Fishing culture will be a good carrier of Chinese culture by virtue of humanity, sociality and naturality and play a role on improving spiritual life of people.

Fishing culture is a cultural phenomenon passed on from generation to generation. Accumulation and transmission, spread and exchange, integration and conflict of fishing culture are the results of long-term accumulations of culture psychology for fishermen, is an interlinked mental characteristic formed in the common process of socialization for fishermen, and is a behavioral mode guided by the mental disposition. It is the valuable treasure of Chinese nation. We should be proud of Chinese fishing culture, so as to spare no efforts to explore and carry out fishing culture of China.

\section{References:}

[1] Qu Jinliang, Reconstruction of Chinese Ocean Cultural Concept, Beijing China Social Sciences Publishing House, 2009, pp. 19-20;

[2] Gu Duan, Anthology of Fishing history, Taibei: Shuxin Press, 1992, pp. 34-35;

[3] Shou Sheng and Chang Huili, Development Study on Chinese Fishery Festivals, Journal of Jinan University(Social Science Version), Vol.(3), 2010, 131-132;

[4] Chen Peizhao and Liu Tao, Discussion on Connotation of Human Culture Change, Journal of Anhui Vocational and Technical College, Vol.21, 2004, pp. 21-26;

[5] Geng Aisheng and Tong Chunfen, the Study on Ocean Fishermen Transformation under the Framework of Marine Fishery Transformation, Anhui Agricultural Sciences, 2012, pp. 18-34;

[6] Jin Zhangchao, et al., Discussion on Development of Fishing Culture in Fresh Water and Promotion to the Industry, Hebei Fishery, 2008, pp. 19-04;

[7] Tong Chunfen and Liu Yue, Change and Cultural Value of Fishing Culture, Journal of Taishan College, Vol.(1), 2014, pp. 52-54;

[8] Yan Lijie, Conversation between Agricultural Culture and Fishing Culture-Comments on Cultural Intermediacy for "Different Hobbies for Different People”, Journal of Shenyang University, 2005, pp. 32-36;

[9] Fang Wei, The Industrial Development Study on Fishing Rural Culture in New Area, Zhoushan Islands, Zhejiang, Zhejiang Ocean University, 2013, pp. 19-04 